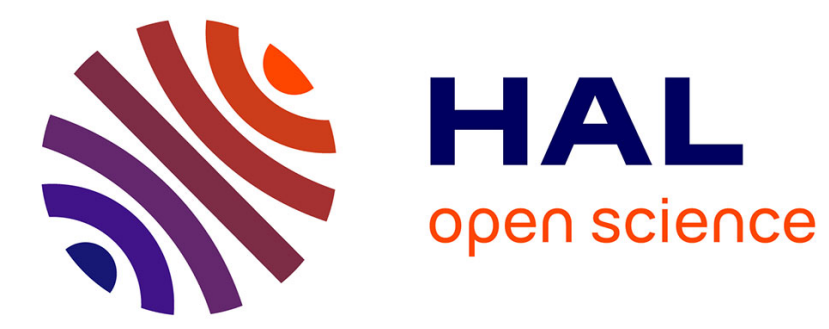

\title{
Studies on Internal Friction Associated with the Motion of Interfaces in Cu-Al-Zn-Ni Alloy
}

H. Shen, Zhen Zhang, Yue Huang, L. Liu, Y. Wang

\section{To cite this version:}

H. Shen, Zhen Zhang, Yue Huang, L. Liu, Y. Wang. Studies on Internal Friction Associated with the Motion of Interfaces in Cu-Al-Zn-Ni Alloy. Journal de Physique IV Proceedings, 1996, 06 (C8), pp.C8-393-C8-396. 10.1051/jp4:1996884 . jpa-00254695

\section{HAL Id: jpa-00254695 https://hal.science/jpa-00254695}

Submitted on 1 Jan 1996

HAL is a multi-disciplinary open access archive for the deposit and dissemination of scientific research documents, whether they are published or not. The documents may come from teaching and research institutions in France or abroad, or from public or private research centers.
L'archive ouverte pluridisciplinaire HAL, est destinée au dépôt et à la diffusion de documents scientifiques de niveau recherche, publiés ou non, émanant des établissements d'enseignement et de recherche français ou étrangers, des laboratoires publics ou privés. 


\title{
Studies on Internal Friction Associated with the Motion of Interfaces in Cu-Al-Zn-Ni Alloy
}

H.M. Shen, Z.F. Zhang, Y.N. Huang, L.B. Liu and Y.N. Wang

National Laboratory of Solid State Microstructures, Nanjing University, Nanjing 210008, China

\begin{abstract}
An internal friction peak associated with the viscous motion of interfaces was measured in the 50$150 \mathrm{kHz}$ range for the $\mathrm{Cu}-\mathrm{Al}-\mathrm{Zn}-\mathrm{Ni}$ sample. The internal friction formula based on the viscous motion of interfaces has been derived. Also, corresponding parameters, which play an important role in shape memory effect such as viscosity coefficient, pinned force constant were obtained.
\end{abstract}

\section{INTRODUCTION}

The internal friction $\left(\mathrm{Q}^{-1}\right)$ associated with first order phase transition in the low frequency range has been known to consist of a transient component, $Q_{t}^{-1}$ and a stationary component, $Q_{s}^{-1}$. The experimental results for the $\mathrm{Q}_{\mathrm{t}}^{-1}$ on cooling or heating at finite rate $(\dot{T})$ showed that the $\mathrm{Q}_{i}^{-1}$ is proportional to $\dot{T} / \mathrm{f}[1-4]$. For the $\mathrm{Q}_{\mathrm{s}}^{-1}$, the mechanism of the stress induced movement of coherent interfaces including phase interfaces, variant and twin boundaries has been widely accepted[1-11]. Most experimental results showed that the $\mathrm{Q}_{3}^{-1}$ is independent of frequency in the low frequency range (below $\mathrm{KHz}$ ). Huang et al.[12] found the $\mathrm{Q}_{\mathrm{s}}^{-{ }^{-}}$ peak to be related to the viscous motion of domain walls in $\mathrm{KH}_{2} \mathrm{PO}_{4}(\mathrm{KDP})$ and $\left(\mathrm{NH}_{2} \mathrm{CH}_{2} \mathrm{COOH}\right)_{3} \mathrm{H}_{2} \mathrm{SO}_{4}$ (TGS) crystals in the higher frequency range. It is not known if there appears the viscous motion of interfaces in martensitic alloys in some higher frequency range. As we know that the mobility of interfaces is important in shape memory effect (SME) because it affects the life and the responding speed of SME. So, in this study, the dynamics of interfaces was studied by using internal friction measurements at higher frequencies and the corresponding parameters such as the spontaneous shear strain, pinned force constant and viscous coefficient, which are closely related to the mobility of interfaces, were obtained for $\mathrm{Cu}-\mathrm{Al}-\mathrm{Zn}$ Ni alloys.

\section{EXPERIMENTS}

A shape memory material with the composition $\mathrm{Cu}-28.76 \mathrm{at} \% \mathrm{Al}-4.76 \mathrm{at} \% \mathrm{Zn}-2.33 \mathrm{at} \% \mathrm{Ni}$ was prepared by vacuum induction melting and homogenized at $970 \mathrm{C}$ for 5 hours. Then, it was cut into sheets of $3 \mathrm{~mm}$ thickness. Samples for internal friction measurements were prepared from above treated sheets by the spark cutting and were kept at $830^{\circ} \mathrm{C}$ for 10 minutes, followed by air quenching to room temperature. The starting and finishing temperature of austenitic transformation, measured by the four ends electric resistance method are $A_{s}=60^{\circ} \mathrm{C}$ and $A_{f}=95^{\circ} \mathrm{C}$, respectively. Internal friction was measured by using the resonant bar apparatus with the static electric drive and detection in the kilohertz range and the piezoelectric composite oscillator in the $50-150 \mathrm{kHz}$ range. X-ray diffraction was conducted to study the structure and spontaneous strains in the $\mathrm{Cu}-\mathrm{Al}-\mathrm{Zn}-\mathrm{Ni}$ sample. 


\section{RESULTS AND DISCUSSION}

Fig. 1 shows the results of internal friction $\left(Q^{-1}\right)$ as a fuction of temperature on heating with $\dot{T}=0.4^{\circ} \mathrm{C} / \mathrm{min}$ in the $\mathrm{kHz}$ range for the $\mathrm{Cu}-28.76 \mathrm{at} \% \mathrm{Al}-4.76 \mathrm{at} \% \mathrm{Zn}-2.33 \mathrm{at} \% \mathrm{Ni}$ sample. An internal friction peak appears at $78^{\circ} \mathrm{C}$ and is independent of the measuring frequency, which reveals that the internal friction is of the static hysteresis type. Moreover, the results measured by using the Marx three component resonator, on heating, in the $50-150 \mathrm{kHz}$ range show that an asymmetrical internal friction peak appears below $\mathrm{A}_{\mathrm{I}}\left(95^{\circ} \mathrm{C}\right)$ as shown in fig. 2. The peak temperature $\left(T_{p}\right)$ increases with the measuring frequency and the relationship between $\operatorname{lnf}$ and $T_{p}^{-1}$ does not obey the Arrhenius relationship, which indicates that the internal friction peak is neither a static hysteresis loss peak nor a thermally activated Debye relaxation peak. The behavior of the internal friction is very similar to that of the internal friction associated with the viscous motion of domain walls in KDP and TGS crystals[12].

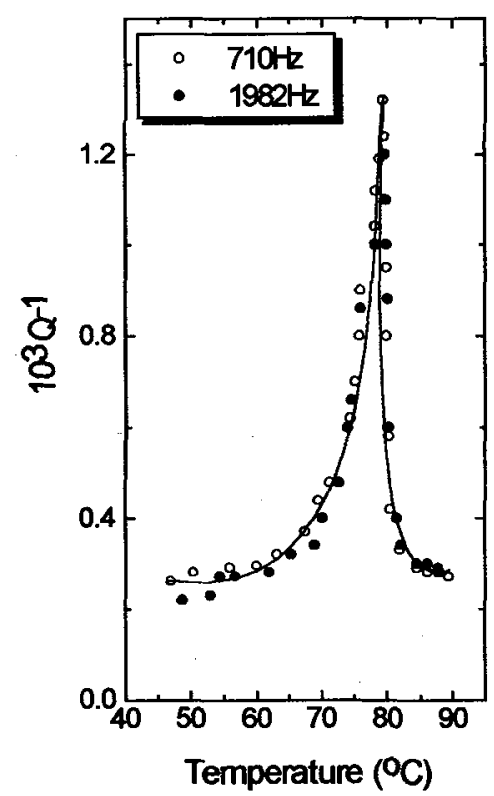

Fig. 1. Internal friction as a function of temperature on heating with $\dot{T}=0.4{ }^{\circ} \mathrm{C} / \mathrm{min}$ at different frequencies $0710 \mathrm{~Hz} \bullet 1982 \mathrm{~Hz}$.

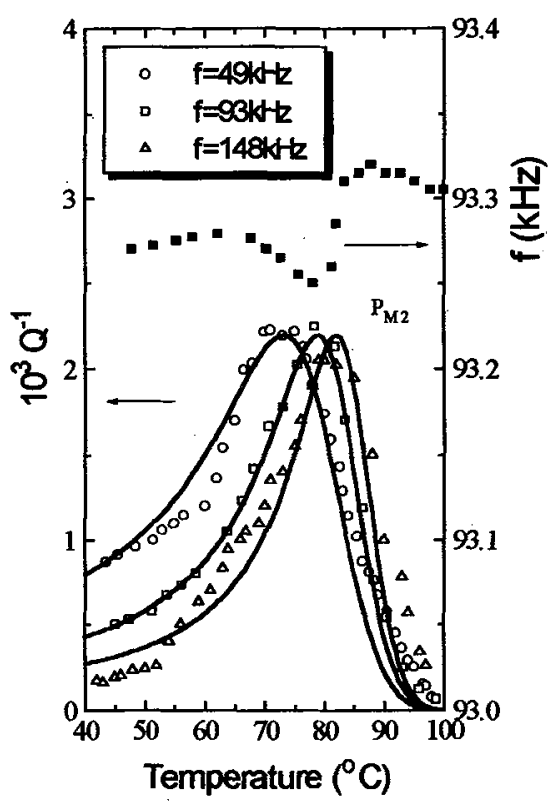

Fig. 2. Internal friction as a function of temperature on heating at different frequencies $\bigcirc 49 \mathrm{kHz} \square 93 \mathrm{kHz} \Delta 148 \mathrm{kHz}$. -results of the computer simulation.

During interfaces motion, there are four forces acting on the unit area of interfaces:

(a) the configuration force $F_{C}$;

(b) the interaction force between nearest-neighbour interfaces $F_{I}$;

(c) the viscous force $-\Gamma \dot{x}$, where $\Gamma$ is the viscous coefficient;

(d) the recovering force $-k_{0} x$ due to defects pinning, where $k_{0}$ is the force constant.

Let $\mathrm{m}$ be the effective mass per unit area of the interface and $x$ be the displacement of the interface under the applied stress, the equation of the movement of an interface is

$$
m \ddot{x}+\Gamma \dot{x}+k_{0} x-F_{I}=F_{C}
$$


It is easily deduced from the energy change due to the change of the interfaces configuration under the applied force that

$$
\begin{aligned}
& F_{l}=-2 C_{i j j} N\left[\varepsilon_{i j}^{(s)}\right]^{2} x \\
& F_{C}=2 \varepsilon_{i j}^{(s)} \sigma_{i j} \\
& \varepsilon_{i j}^{(d)}=\varepsilon_{i j}^{(s)} x / d
\end{aligned}
$$

where $\varepsilon_{i j}^{(s)}$ is the spontaneous shear strain, $C_{i j j}$ is the corresponding shear modulus, $N$ is the average number of parallel interfaces per unit perpendicular distance. So, $N=d^{I}$ where $d$ is the distance between nearestneighbour interfaces, $\sigma_{i j}$ is the effective shear stress which can drive interfaces to move, $\varepsilon_{i j}^{(d)}$ is the shear strain caused by interfaces moving under applied stress.

Let $\sigma_{i j}=\sigma_{o} e^{i \omega t}$ and when $\omega^{2<<k / m}$ where $k=k_{o}+2 C_{i j i} N\left[\varepsilon_{i j}^{(s)} J^{2}\right.$, the internal friction $\left(\mathrm{Q}^{-1}\right)$ can be obtained from formulas (1)-(4)

$$
Q^{-1}=\frac{2 N\left[\varepsilon_{i j}^{(s)}\right]^{2}}{J k} \frac{\omega \tau}{1+\omega^{2} \tau^{2}}
$$

where $\tau=\Gamma / k$ is the relaxation time.

According to the expression obtained by Combs and Yip[13] for the viscous coefficient

$$
\Gamma=A e^{-B /\left(T_{c}-T\right)}
$$

where $A$ and $B$ are constants, $T_{c}$ is the corresponding $\mathrm{A}_{f}$ on heating in martensitic alloys. We can obtain $A / k=7 \times 10^{-4}$ second and $B=130 \mathrm{~K}$ by using the computer simulation based on the internal friction experimental results as shown in fig. 2 . In order to obtain the effective force constant $k$ from the formula (5), we calculated the spontaneous shear strain, $\varepsilon_{i j}^{(s)}$, density of interfaces $N$ and modulus $J^{-I}$ based on the results of X-rav diffraction, metallographic observation and internal friction measurements.

The results of X-ray diffraction in the $\mathrm{Cu}-\mathrm{Al}-\mathrm{Zn}$-Ni sample show that the structure of the orthorhombic $\mathrm{r}_{1}{ }^{\prime}$ martensitic is $\mathrm{Cu}_{3} \mathrm{Ti}$ type with lattice parameters, $a=0.4382 \mathrm{~nm}, b=0.5356 \mathrm{~nm}, c=0.4222 \mathrm{~nm}$ and the principal/axes in $r_{1}^{\prime}$ martensitic phase are parallel to the directions of $[10 \overline{1}],[010],[101]$ of $\beta_{1}$ cubic parent phase with $a_{0}=0.5836 \mathrm{~nm}$, which is similar to the results obtained by $K$. Otsuka et al.[14]. In the principal axes coordinate system of the $r_{1}{ }^{\prime}$ orthorhombic phase, we can obtain the strains due to martensitic phase transformation based on the results of $\mathrm{X}$-ray diffraction experiments and the Neumann principle.

$$
\begin{array}{ll}
\varepsilon_{11}=\left(a-\frac{\sqrt{2}}{2} a_{0}\right) / \frac{\sqrt{2}}{2} a_{0}=0.061, & \varepsilon_{22}=\left(b-a_{0}\right) / a_{0}=-0.082 \\
\varepsilon_{33}=\left(C-\frac{\sqrt{2}}{2} a_{0}\right) / \frac{\sqrt{2}}{2} a_{0}=0.022, & \varepsilon_{i j}(i \neq j)=0
\end{array}
$$

So, the spontaneous shear strain in $\beta_{1}$ cubic phase coordinate system

$$
S_{i j}^{(s)}=2 \sum_{i, j=1}^{3} a_{1 i} a_{3 i} \varepsilon_{i j}=0.0389 .
$$

where $a_{11}=a_{31}=a_{33}=\sqrt{2} / 2, a_{13}=-\sqrt{2} / 2, a_{12}=a_{32}=0$

The average density of interfaces $\mathrm{N}$ is $1.2 \times 10^{5} / \mathrm{m}$ based on the results of metallographic observation. The elastic modulus is $1.5 \times 10^{5} \mathrm{MPa}$ based on the formula $\mathrm{J}^{-1}=4 \rho \mathrm{P}^{2} \mathrm{f}^{2}$ where $\rho=7.59 \mathrm{~g} / \mathrm{cm}^{3}, 1=2.42 \mathrm{~cm}$ and $\mathrm{f}=93$ kHz.

The pinned force constant $\mathrm{k}_{0}, \mathrm{k}$ and the viscous coefficient $\Gamma$ can be obtained based on the results mentioned above and the formulas (5) and (6). They are

$\mathrm{k}=1.6 \times 10^{15} \mathrm{~N} / \mathrm{m}^{3}, \mathrm{k}_{0}=1.54 \times 10^{15} \mathrm{~N} / \mathrm{m}^{3}$ and $\Gamma=11.2 \times 10^{11} \exp [-130 /(363-\mathrm{T})] \mathrm{Kg} / \mathrm{m}^{2} \mathrm{~s}$. 


\section{CONCLUSION}

The internal friction peak in the $50^{-}-150 \mathrm{kHz}$ range is neither a static hysteresis loss nor a thermally activated Debye relaxation peak. It relates to the viscous motion of interfaces. The viscous coefficient and the pinned force constant have been obtained in the $\mathrm{Cu}-\mathrm{Al}-\mathrm{Zn}-\mathrm{Ni}$ by using internal friction measurements, metallographic observation, X-ray diffraction analysis and the model of the interfaces viscous movement.

\section{ACKNOWLEDGEMENT}

This work was supported by the National Science Foundation of China.

\section{REFERENCES}

1. Wang Y.N., Yang Z.J., Zhu H., Ma J.C., Journal of Nanjing University 7 (1963) 1

2. Postnikov V.S., Gridnev S.A., Darinski B.M. and Sharshakov I.M., NUOVO CIMENTO, 33B (1976) 324

3. Gridnev S.A. and Postnikov V.S., Ferroelectrics 29 (1980) 157

4. Delorme J., Schmid R., Robin M. and Gobin P., J. de Phys., 32 (1970) C2-101

5. Christian J.W., J. Inst. Metals. 93 (1965) 546

6. Dejonghe W., DeBatist R. and Delaey L., Scripta Metall. 10 (1976) 1125

7. Mercier O. and Melton K.N., Acta Met. 27 (1979) 1467

8. Yang Z.J., Zou Y.F., Zhang Z.F. and Wang Y.N., Acta Metall. Sinica 18 (1982) 21

9. Wang Y.N., Sun W.Y., Shen H.M., Phys. Stat. Sol. (a) 102 (1987) 279

10. Snead C.L., Welch D., J. de Phys. 46 (1985) C10-589

11. Wang Y.N., Huang Y.N., J. Alloys and Compounds 211/212 (1994) 356

12. Huang Y.N., Wang Y.N. and Shen H.M., Phys. Rev. B 46 (1992) 3290

13. Comb J. A. and Yip S., Phys. Rev. B 11 (1975) 3535

14. Otsuka K. and Shimizu K., Trans. Japan Inst. Metals 15 (1974) 103 